\title{
Geochemical Characteristics of Soil Gas and Strong Seismic Hazard Potential in the Liupanshan Fault Zone (LPSFZ)
}

\author{
Huiling Zhou $\mathbb{D}^{1,2}$ Hejun Su $\mathbb{D}^{1,2}$ Hui Zhang, ${ }^{1,2}$ Chenhua Li, ${ }^{1,2}$ Dongzheng Ma, \\ and Ronglong $\mathrm{Bai}^{3}$ \\ ${ }^{1}$ The National Geophysics Observation Station, East Mountains West Road 450, Lanzhou, Gansu Province 730000, China \\ ${ }^{2}$ Lanzhou Institute of Seismology, China Earthquake Administration, East Hills West Road 450, Lanzhou 730000, China \\ ${ }^{3}$ Institute of Earth Science, Chengdu University of Technology, Chengdu 610059, China
}

Correspondence should be addressed to Hejun Su; 15609413188@163.com

Received 16 October 2019; Revised 27 January 2020; Accepted 11 February 2020; Published 17 October 2020

Academic Editor: Umberta Tinivella

Copyright (c) 2020 Huiling Zhou et al. This is an open access article distributed under the Creative Commons Attribution License, which permits unrestricted use, distribution, and reproduction in any medium, provided the original work is properly cited.

\begin{abstract}
Eight soil gas measurements were performed in the Liupanshan fault zone (LPSFZ) to observe the concentration and flux of soil gas radon $(\mathrm{Rn})$ and $\mathrm{CO}_{2}$ in October 2017 and October 2018. By combining the historical strong earthquake background and modern seismic activity of the fault zone, the relation between the geochemical distribution characteristics of soil gas and the seismicity of the fault zone was studied herein. Furthermore, the strong seismic hazard potential of the fault zone was discussed. Results show that the concentration of soil gas $\mathrm{Rn}$ and $\mathrm{CO}_{2}$ considerably varies in the northern segment of the LPSFZ and is relatively stable in the southern segment. The spatial distribution of the concentration intensity and flux is strong in the north and weak in the south. However, the southern segment of the LPSFZ has a seismic gap that has not been ruptured by strong earthquakes with $\mathrm{Ms} \geq 6.5$ for the last 1400 years, whereas the seismic activity in the northern segment is relatively frequent, indicating that the fault zone locking degree of the southern segment is higher than that of the northern segment. This observation is completely consistent with the geochemical characteristic distribution of soil gas. Therefore, the southern segment of the LPSFZ should be considered a hazardous segment, where major or strong earthquakes can occur in the future.
\end{abstract}

\section{Introduction}

The crustal fluid is an important constituent of the Earth and a ubiquitous and dynamic component of the Earth's crust. The subsurface fluid actively participates in various dynamic interactions in the crust and is vital in the exchange of material and energy among various layers of the Earth. It is closely related to the seismogenic process and the occurrence of earthquakes. Earthquakes are caused by a tectonic evolution accompanied by the exchange of matter and energy deep inside the Earth [1-4], which is mainly transmitted via the release of fluid through active faults and fractures at different depths [5] because faults and fractures are preferential migration pathways for gases (e.g., $\mathrm{CO}_{2}$ and radon $(\mathrm{Rn}))$ in the deep crust to migrate upward to the surface owing to their enhanced permeability and porosity relative to the surrounding rocks [6-8]. Active faults can provide pathways for gas leaks from the solid Earth because they usually increase the permeability of soils [9-11]. Soil gas concentration and flux surveys along active fault zones are very important for earthquake research and prediction [12-16]. Recent advances in gas geochemistry have established potential in the study of both fault activity and seismic hazards. Soil gas geochemical surveys in seismically active areas have been conducted across the world, and some anomalies appearing before earthquakes have been identified [17-20]. Rn often shows significant anomalies at fault zones concerning earthquakes [21-24]. Anomalously high Rn volume activity fluctuations were observed several hours to a few days before an earthquake $\left(M_{\mathrm{L}}>3\right)$ that occurred in northern Taiwan [8]. Similarly, Rn volume activities in the Arax basin (Armenia) were observed to vary before and after earthquakes [25]. A large amount of observed Rn data in ground water and soil has been collected in China $[26,27]$. 
Some precursors have been proposed for earthquakes [28], and various geochemical anomalies of gas species were determined near the fault zones before the occurrence of some large earthquakes in China [29, 30]. Furthermore, a clear correlation between $\mathrm{Rn}$ anomalies and fault traces in sedimentary basins has also been reported in many regions of the world, such as Fucino Plain and Northern Calabria, Italy [31]; Neuwied Basin, Germany [32]; and France [33], where seismic activities and high tectonic strain rates occur. $\mathrm{CO}_{2}$ is the second most abundant magmatic gas after $\mathrm{H}_{2} \mathrm{O}$ and is the main gas investigated during diffuse degassing studies as well as at many permanent stations using the accumulation chamber method (ACM) [34, 35]. Soil gas anomalies are usually complex because they are subject to multiple influences (atmospheric, biogenic, organic, and from the deep crust and mantle [23, 25, 36, 37]) and occasionally, their relationships with seismic events can be ambiguous [4, 7, 38, 39]. Accordingly, if soil gas observations in fault zones become a useful method of fault activity assessment and seismic forecasting, further analysis of their relationships is required and the source identification of soil gas in the seismically active areas is a prerequisite. General overviews of the geochemical, structural, and seismic features in tectonically active areas have shown some evidence of a correlation between soil gas geochemistry anomalies and tectonic activities. Recent studies regarding soil gas geochemistry within fault zones and its relationship with earthquake activities further indicate that it can be used to monitor earthquakes.

The Liupanshan fault zone (LPSFZ) is located in the northeastern boundary of the Qinghai-Tibet Plateau and is an important part of the North-South seismic zone. It undergoes frequent seismic activities and is a key area for earthquake prevention in Northwest (NW) China. Recently, because of the occurrence of several major earthquakes in the western, eastern, and southern boundaries of the Qinghai-Tibet Plateau, particularly after the M8.0 Wenchuan earthquake in 2008, significant deformation and gravitational changes occurred in the same area along the North-South seismic zone. The hazard of major earthquakes in the future has attracted significant attention from researchers [37, 38, 40]. No major earthquake of Ms $\geq 7$ has occurred for 396 years, and no strong earthquake of $\mathrm{Ms} \geq 6.5$ has occurred for nearly 96 years in the northern segment of the LPSFZ since the Ms7 earthquake in Guyuan, Ningxia, 1622, and the M6.5 earthquake in southern Guyuan, 1921. Moreover, no strong earthquake of $\mathrm{Ms} \geq 6.5$ has occurred in the middle and southern segments of the LPSFZ for at least 1000 years. Therefore, studying the seismic occurrence capacity and seismic hazard background of the LPSFZ is of great significance. At present, the detection of soil gas in the LPSFZ is relatively rare. The geochemical data are relatively scarce, and only a few studies have been conducted. Therefore, this study selected LPSFZ as the research area and analyzed the observation of soil gas $\mathrm{Rn}$ and $\mathrm{CO}_{2}$ across the fault strike to investigate the geochemical characteristics of this fault zone, synthesize its seismic activities, and investigate its strong earthquake hazard background.

\section{Tectonic Dynamics Environment of the LPSFZ}

This study focused on the narrow definition of the LPSFZ, mainly in the eastern foothill of the LPSFZ. It is in the direction of NNW-nearly SN spreading in the northwest of Guyuan, Ningxia. It extends from Xiangnan to the Longxi basin via Huating, Gansu. The total belt length is approximately $175 \mathrm{~km}$. The LPSFZ is located at the junction between the northeastern boundary of the Qinghai-Tibet plateau and the Ordos block. Structurally, it is located in the transition zone between the boundary of the Ordos block in the western part of the North China fault block and the Qilian fault folding zone in the northeastern part of the Qinghai-Tibet block [41]. On the north side of Guyuan, the LPSFZ is connected with the southeastern segment of the NW-oriented Haiyuan fault zone. Between Longxian and Jingning, the LPSFZ is sinistrally truncated by the NW-oriented Longxian-Baoji fault zone. The latter mainly comprises faults, such as Guguan-Baoji and Longxian-Qishan-Mazhao (Figure 1). Adjacent to the LPSFZ is an SN-oriented Xiaoguanshan fault developed on the east side. It is the southern segment of the SN-oriented Niushoushan-Luoshan/Yunyunshan-Xiaoguanshan fault belt that controls the western boundary of the Ordos block and terminates southward near Huating. In the Longzhong basin to the west of the LPSFZ, there are several NW- and NNW-oriented secondary fault zones, such as the Maqishan-Huining fault.

Geological and active tectonic studies have proven that the LPSFZ has Late Quaternary activities. The eastern foothill fault zone of Liupanshan is a reverse-sinistral strike-slip fault of Holocene activities. Along the fault zone, Neogene thrusts are observed to be overburdened by the Quaternary and a series of young faulted landforms, such as sinistral dislocation of the water system, steep ridges, and trenches, is developed. The Quaternary horizontal sliding rate is 1$3 \mathrm{~mm} \cdot \mathrm{a}^{-1}$, whereas the vertical sliding rate is approximately $0.9 \mathrm{~mm} \cdot \mathrm{a}^{-1}$. Simultaneously, geological and active tectonic structure investigations have demonstrated that the NWoriented Haiyuan fault zone and the Longxian-Baoji fault zone, which are distributed in the northwest and southeast of the LPSFZ, respectively, are mainly sinistral strike-slip. From the perspective of a larger regional scale, the driving force of the Liupanshan tectonic belt activity is mainly caused by the horizontal extrusion of the northeastern boundary of the Qinghai-Tibet block (Qilian + Qaidam block) to the east, which is blocked by the horizontal extrusion of the relatively stable Ordos block to the east of Liupanshan. Moreover, the Liupanshan tectonic belt is superimposed to bear the leftlateral rotation of the two strike-slip fault zones because of the right-grid region between the two strike-slip fault zones of Haiyuan and Longxian-Baoji, which are restricted in the geometrical constraints of the fault. The leveling movement is concentrated in the right-order zone and is converted in the form of an enhanced level shortening the deformationreverse movement.

This area is an important part of the North-South seismic zone. It has frequent seismic activities and is a key area for earthquake prevention and prediction in the northwest 


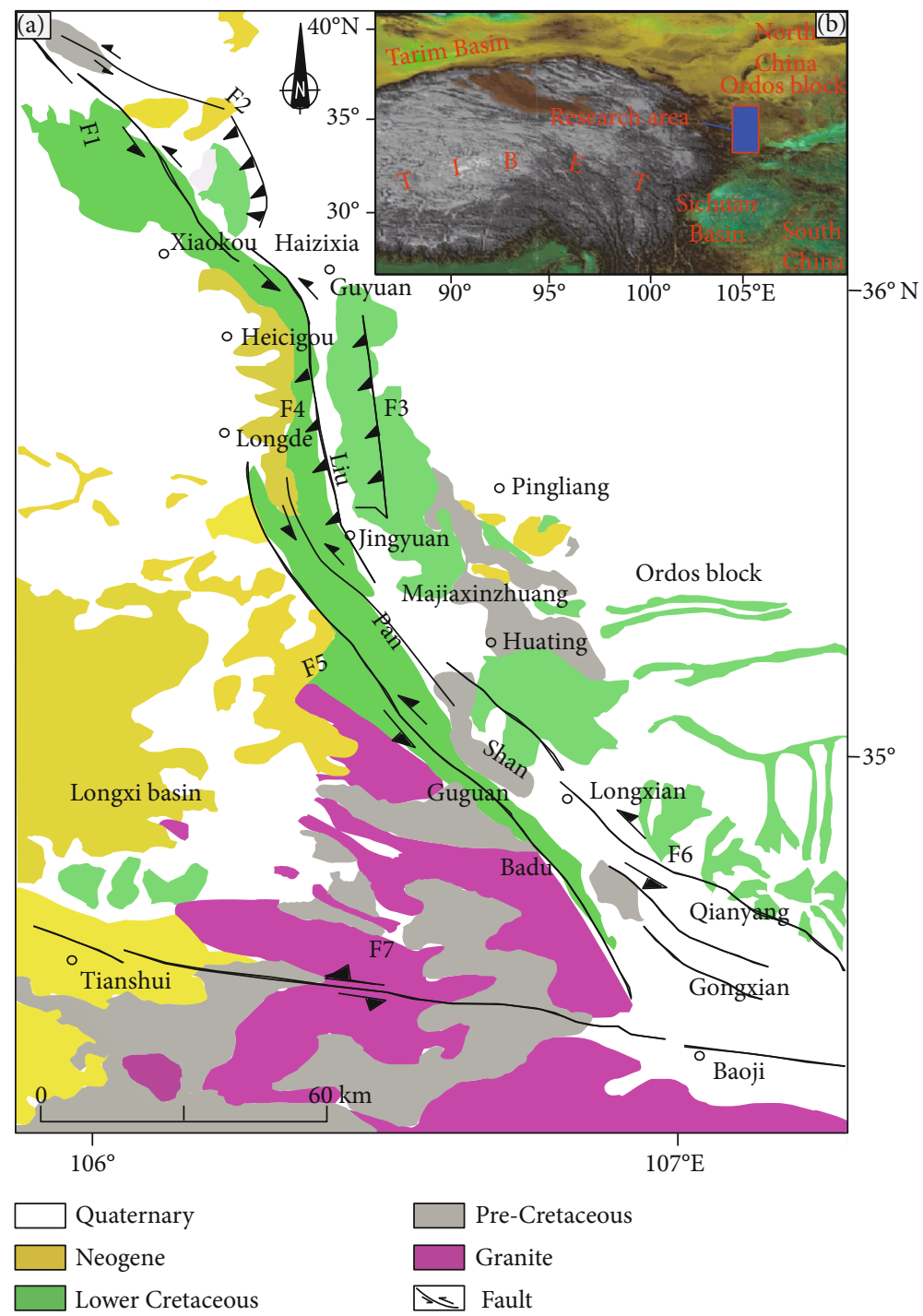

FIGURE 1: Schematic of the LPSFZ and its adjacent active faults: F1: Haiyuan fault zone; F2: Madongshan fold-thrust belt; F3: Xiaoguanshan fault zone; F4: LPSFZ, F5: West foothill of the LPSFZ; F6: Longxian-Qishan-Mazhao fault; and F7: fault zone of the northern boundary of Western Qinling.

part of China. The area has attracted long-term attention and follow-up from earthquake researchers. Recently, with the occurrence of several major earthquakes on the western, eastern, and southern boundaries of the Qinghai-Tibet plateau, particularly after the M8.0 Wenchuan earthquake in 2008, significant deformation and gravitational changes occurred in the same area along the North-South seismic zone. The hazard of major earthquakes in the future has attracted significant attention from researchers [41, 42]. This area has the tectonic conditions for the occurrence of strong earthquakes or even large earthquakes. The future seismic hazard tracking analysis will become an important issue in the field.

\section{Survey Line Layout and Measurement Method}

3.1. Soil Gas Concentration Measurements. Soil gas measurements were performed in the field at eight measurement surveys (i.e., SYZ, HJZ, YLC, LPC, DZC, SLGY, XXC, and LDC) covering the LPSFZ (Figure 2, Table 1), where the HJZ, YLC, LPC, and DZC (HT1-HT4) were located in the northern segment of the LPSFZ. According to the segmentation of the LPSFZ active tectonics, the DZC, SLGY, XXC, and LDC (HT5-HT8) were located in the middle and south of the LPSFZ. The surveying lines were perpendicular to the fault layout, and 28-35 measuring points were laid out for each strike line according to the fault condition, with a total of 255 measuring points. The distance between each measuring point was approximately $10 \mathrm{~m}$, and an intensive measurement was performed near the fault plane and obvious structural parts, such as steep ridges. To avoid possible meteorological effects on the soil gas concentrations, the soil gas survey was conducted during a period of stable meteorological conditions from October 2017 to October 2018. No dramatic climatic variations were observed during this monitoring period. The meteorological conditions of each 


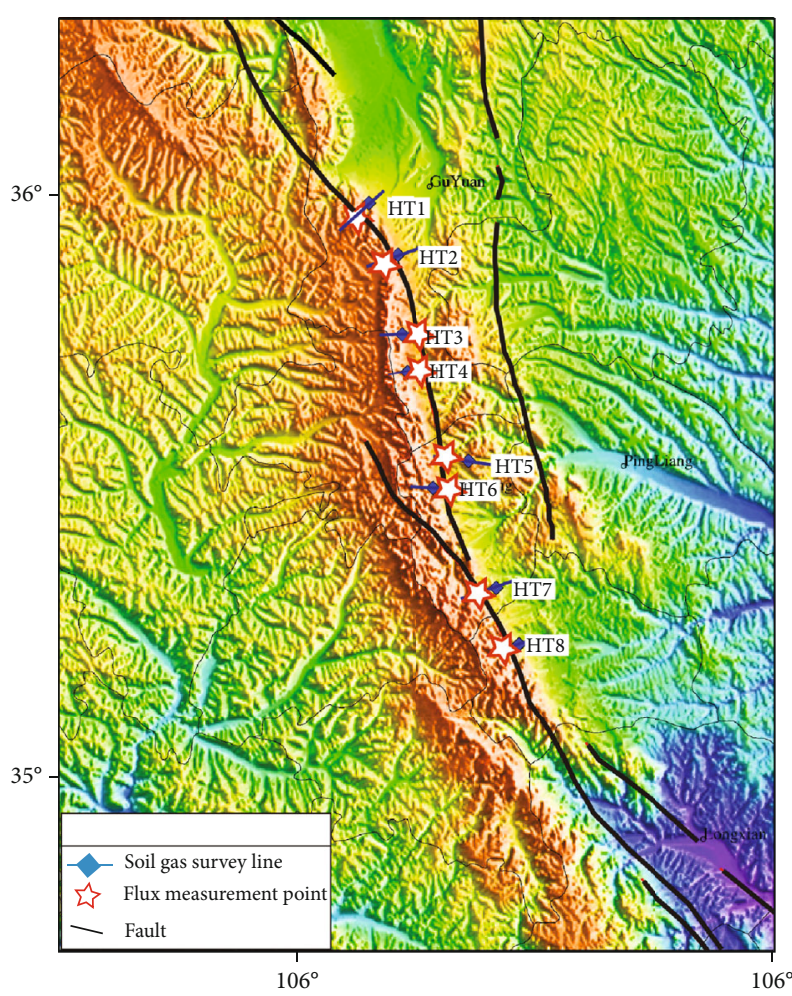

Figure 2: LPSFZ soil gas survey lines and flux measurement point layout.

TABLE 1: List of the LPSFZ measurement point location and number of measurement points.

\begin{tabular}{lccccc}
\hline Site & No. & $\begin{array}{c}\text { Longitude } \\
\left({ }^{\circ} \mathrm{E}\right)\end{array}$ & $\begin{array}{c}\text { Latitude } \\
\left({ }^{\circ} \mathrm{N}\right)\end{array}$ & $\begin{array}{c}\text { Number of } \\
\text { measurement } \\
\text { points }\end{array}$ & $\begin{array}{c}\text { Length of } \\
\text { survey } \\
\text { lines }(\mathrm{m})\end{array}$ \\
\hline SYZ & HT1 & 106.14868 & 35.98575 & 35 & 400 \\
HJZ & HT2 & 106.20968 & 35.8978 & 30 & 355 \\
YLC & HT3 & 106.21845 & 35.7615 & 28 & 270 \\
LPC & HT4 & 106.22953 & 35.69698 & 29 & 560 \\
DZC & HT5 & 106.28555 & 35.4980333 & 37 & 485 \\
SLGY & HT6 & 35.54448 & 35.54448 & 30 & 470 \\
XXC & HT7 & 106.4181 & 35.32688 & 32 & 335 \\
LDC & HT8 & 106.4661 & 35.2297 & 34 & 370 \\
\hline
\end{tabular}

measuring point in the two periods are relatively stable. The measurement items were $\mathrm{Rn}$ and $\mathrm{CO}_{2}$. The $\mathrm{Rn}$ concentrations were measured using an AlphaGUARD detector (model PQ2000, Saphymo GmbH, Germany). The AlphaGUARD Rn detector uses a pulse ionization chamber detector. After the measured gas enters the ionization chamber detector of AlphaGUARD, alpha particles produced by Rn and progeny decay forms voltage pulse at the collector (cathode) under the action of the electric field. These pulses are recorded using a counter. The number of pulses recorded is proportional to the number of alpha particles, i.e., Rn concentration. According to the requirements of AlphaGUARD P2000, we measure 15-20 numbers in the measurement process, remove the first number in the data processing process, and assume the average value of the number after that to represent the $\mathrm{Rn}$ concentration. $\mathrm{CO}_{2}$ concentrations were measured using a portable infrared $\mathrm{CO}_{2}$ monitor (GXH-3010, Institute of Beijing HUAYUN Analytical Instrument Co., Ltd., http://www.hyaii.com, measuring range of $0-50,000 \mathrm{ppm}$, accuracy of $4 \%$ of reading). All samples were collected using a stainless-steel probe driven into the ground to $0.8-1.0-\mathrm{m}$ depth depending on the soil consistency and thickness (Figure 3). This sample depth was chosen to minimize the effects of the meteorological variables [43-45].

3.2. Soil Gas Flux Measurements. The flux of the fault soil gas was measured using the closed accumulation chamber method. The point of the flux measurement is that with the highest $\mathrm{Rn}$ and $\mathrm{CO}_{2}$ concentration on each fault plane. The soil $\mathrm{Rn}$ and $\mathrm{CO}_{2}$ flux data were simultaneously collected (Figure 3). The employed instrument of the soil flux measurements comprised an inverted circular accumulation hemispherical chamber with a volume of $1.689 \times 10^{-2} \mathrm{~m}^{3}$, radius of $0.2 \mathrm{~m}$, and portable infrared $\mathrm{CO}_{2}$ monitor ( $\mathrm{GXH}$ 3010 and RAD7 Rn monitor, Durridge Company Inc.). Gas was circulated from the chamber to GXH-3010 and then back into the chamber via a small-diameter plastic tube (inner diameter: $3 \mathrm{~mm}$ ) connected to a $0.5 \mathrm{~L} \mathrm{~min}^{-1}$ air pump. The mixing of the gas in the chamber was facilitated by the recirculation of four quarter-arc shaped reinjecting the circulating gas. The accumulation chamber was connected in a closed-loop configuration to the RAD7 Rn monitor (Durridge Company Inc.). RAD7 uses a solid-state alpha detector. It is composed of semiconductor materials (usually silicon), which can directly convert the radiation into signals. An important advantage of solid-state detection devices is the ability to electronically determine the energy of each particle. Therefore, $\mathrm{Rn}$ and thorium gas, as well as noise signals, can be directly identified. The instrument drew gas from the accumulation chamber via the desiccant (diorites) and an inlet filter into the measurement chamber. Then, gas was returned to the accumulation chamber from the RAD7 outlet [46]. The temporal variations of the fault soil gas concentration inside the chamber during the flux measurement were recorded using a computer that also calculated the temporal rate of increase in the soil gas concentration at $t=0$, $(\partial C / \partial t)_{t=0}$ by exponential regression methods $[47,48]$. The soil $\mathrm{CO}_{2}$ flux (expressed as $\mathrm{gm}^{-2} \mathrm{day}^{-1}$ ) was calculated using the following equation [49-51]:

$$
F=\rho \times \frac{V}{A} \times(\partial C / \partial t) t=0
$$

where $F$ is the soil flux; $\rho$ is the density of the gas under the standard condition; and $V\left(\mathrm{~m}^{3}\right)$ and $A\left(\mathrm{~m}^{2}\right)$ are the volume and bottom area of the chamber, respectively.

\section{Data Analysis and Results}

4.1. Distribution Characteristics of the Soil Gas $\mathrm{Rn}$ and $\mathrm{CO}_{2}$ Concentration in the LPSFZ. Table 2 presents the results of the first survey period in October 2017. The maximum Rn 


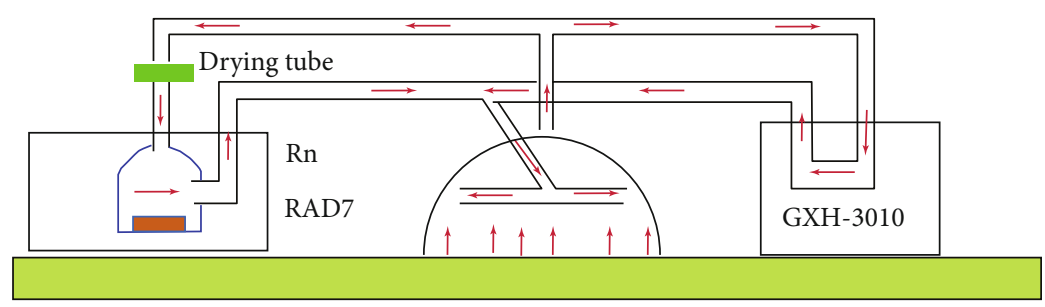

(a)

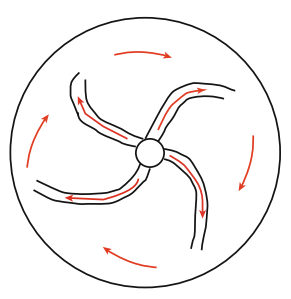

(b)

Figure 3: Schematic of the soil gas $\mathrm{CO}_{2}$ and Rn flux: (a) sketch used for the measurement of $\mathrm{CO}_{2}$ and Rn flux combined with the sampling of $\mathrm{CO}_{2}$ and Rn efflux; (b) sketch of mixing of gas in the chamber.

TABLE 2: Results of the soil gas Rn and $\mathrm{CO}_{2}$ concentrations of the LPSFZ in 2017 and 2018.

\begin{tabular}{|c|c|c|c|c|c|c|c|c|}
\hline \multirow{3}{*}{$\begin{array}{l}\text { Time } \\
\text { Gas species } \\
\text { Site }\end{array}$} & \multicolumn{4}{|c|}{ October 2017} & \multicolumn{4}{|c|}{ October 2018} \\
\hline & \multicolumn{2}{|c|}{$\mathrm{Rn}(\mathrm{Bq} / \mathrm{L})$} & \multicolumn{2}{|c|}{$\mathrm{CO}_{2}(\%)$} & \multicolumn{2}{|c|}{$\mathrm{Rn}(\mathrm{Bq} / \mathrm{L})$} & \multicolumn{2}{|c|}{$\mathrm{CO}_{2}(\%)$} \\
\hline & Maximum & Mean & Maximum & Mean & Maximum & Mean & Maximum & Mean \\
\hline SYZ & 54.00 & 26.09 & 0.86 & 0.38 & 126 & 30.29 & 0.71 & 0.47 \\
\hline $\mathrm{HJZ}$ & 111.00 & 28.46 & 1.79 & 0.42 & 112 & 29.55 & 1.55 & 0.73 \\
\hline YLC & 95.00 & 32.53 & 1.41 & 0.99 & 95 & 31.46 & 1.36 & 0.67 \\
\hline LPC & 83.00 & 29.86 & 1.41 & 0.84 & 84 & 28.38 & 2.58 & 1.29 \\
\hline DZC & 139.00 & 31.95 & 1.82 & 0.34 & 151 & 33.78 & 1.27 & 0.79 \\
\hline SLGY & 76.00 & 23.6 & 1.11 & 0.94 & 89 & 36.03 & 0.93 & 0.67 \\
\hline XXC & 94.00 & 27.17 & 1.4 & 0.79 & 119 & 44.24 & 1.81 & 0.79 \\
\hline LDC & 46.00 & 16.73 & 2.4 & 0.42 & 85 & 32.82 & 3.44 & 1.44 \\
\hline
\end{tabular}

concentration in the soil gas ranged from 46.00 to 139.00 Bq/L, with $\mathrm{DZC}$ demonstrating the highest value. The seismic background values ranged from 16.73 to $32.53 \mathrm{~Bq} / \mathrm{L}$; the maximum value was measured at YLC, which is located in the northern segment of the LPSFZ. The maximum $\mathrm{CO}_{2}$ concentration was between $0.86 \%$ and $2.4 \%$; the maximum value was located in the southern part of the LDC. The background value was between $0.34 \%$ and $0.99 \%$; the maximum value was located in the YLC. The second survey period was in October 2018. The maximum $\mathrm{Rn}$ concentration in the soil gas ranged from 85 to $151 \mathrm{~Bq} / \mathrm{L}$, with the maximum value at DZC. The background values were between 28.38 and $44.24 \mathrm{~Bq} / \mathrm{L}$, with the maximum value at XXC. The maximum $\mathrm{CO}_{2}$ concentration was between $0.71 \%$ and $3.44 \%$, with the maximum value located in LDC. The background values were between $0.47 \%$ and $1.44 \%$, with the maximum value located in LDC. We studied the stability of the soil gas concentration of the LPSFZ by conducting a comparative study on the difference between the measured maximum and background values of each site between 2017 and 2018. Table 3 and Figure 4 show the results.

Figure 4 shows that the maximum value of $\mathrm{Rn}$ was very stable and almost unchanged in the HJZ, YLC, and LPC, except for the northernmost SYZ site, which had the largest variation range (up to $72 \mathrm{~Bq} / \mathrm{L}$ ). After $\mathrm{DZC}$, the maximum value gradually increased from north to south and the amplitude of the increase was larger in the southern sites. The background value of $\mathrm{Rn}$ remained relatively stable in the northern and middle segments, whereas sites XXC and LDC in the southern segment of the fault zone along with site SLGY had a larger increase trend. Except for the relatively
TABle 3: Difference in the LPSFZ soil gas $\mathrm{Rn}$ and $\mathrm{CO}_{2}$ measurements between 2017 and 2018.

\begin{tabular}{|c|c|c|c|c|}
\hline $\begin{array}{l}\text { Measurement } \\
\text { item } \\
\text { Measurement } \\
\text { site }\end{array}$ & $\begin{array}{l}\text { Difference } \\
\text { in the } \\
\text { maximum } \\
\mathrm{Rn}(\mathrm{Bq} / \mathrm{L})\end{array}$ & $\begin{array}{l}\text { Difference } \\
\text { in the } \\
\text { average } \mathrm{Rn} \\
(\mathrm{Bq} / \mathrm{L})\end{array}$ & $\begin{array}{l}\text { Difference } \\
\text { in the } \\
\text { maximum } \\
\mathrm{CO}_{2}(\%)\end{array}$ & $\begin{array}{l}\text { Difference } \\
\text { in the } \\
\text { average } \\
\mathrm{CO}_{2}(\%)\end{array}$ \\
\hline SYZ & 72.00 & 4.20 & -0.15 & 0.09 \\
\hline HJZ & 1.00 & 1.09 & -0.24 & 0.30 \\
\hline YLC & 0.00 & -1.08 & -0.05 & -0.31 \\
\hline LPC & 1.00 & -1.48 & 1.17 & 0.45 \\
\hline DZC & 12.00 & 1.83 & -0.55 & 0.45 \\
\hline SLGY & 13.00 & 12.43 & -0.18 & -0.27 \\
\hline XXC & 25.00 & 17.07 & 0.41 & 0.00 \\
\hline LDC & 39.00 & 16.09 & 1.04 & 1.02 \\
\hline
\end{tabular}

stable $\mathrm{CO}_{2}$ in the northern segment, the maximal $\mathrm{CO}_{2}$ increment was similar to $\mathrm{Rn}$, which increased from north to south, and the amplitude gradually increased in the southern segment. The change of the $\mathrm{CO}_{2}$ background value in the northern and middle segments was relatively small but varied relatively high in the southern segment with an increase of 1.02 in the LDC site.

A comparison of the difference between the maximum measured value and the background value of the two periods showed that $\mathrm{Rn}$ and $\mathrm{CO}_{2}$ had a smaller amplitude variation and a stronger stability from the northern segment to the middle segment of the LPSFZ, whereas the variations of the sites in the southern segment were larger, showing an 


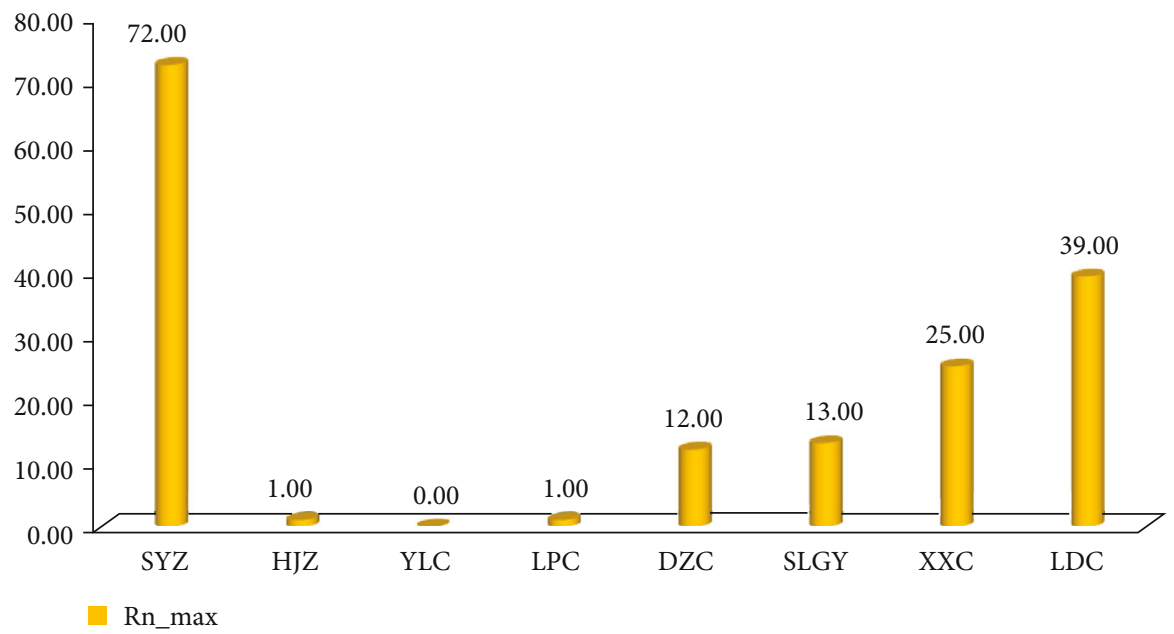

(a)

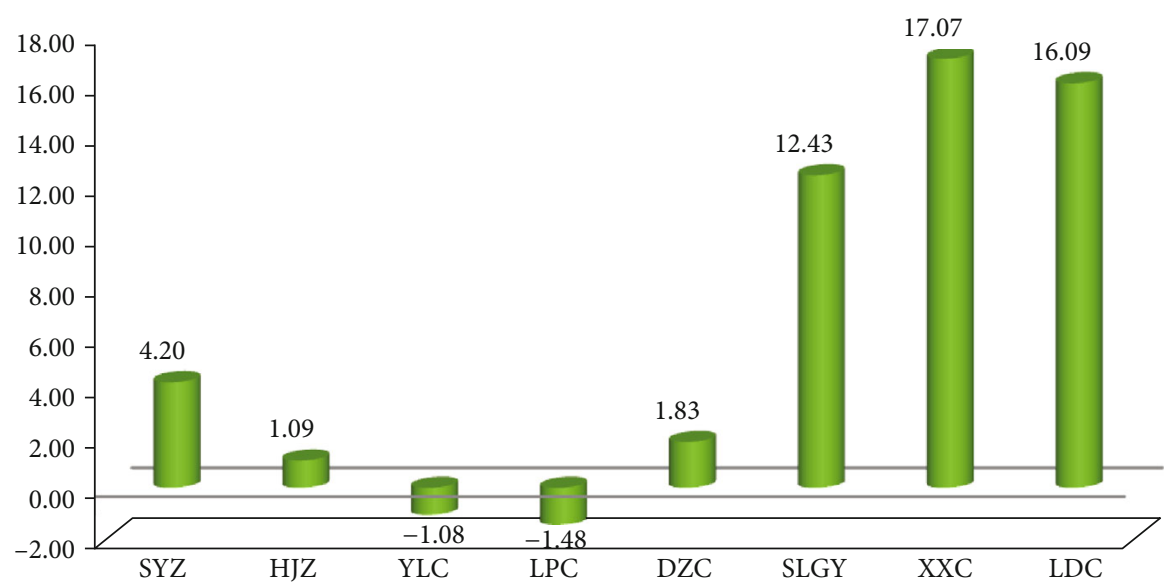

Rn_mean

(b)

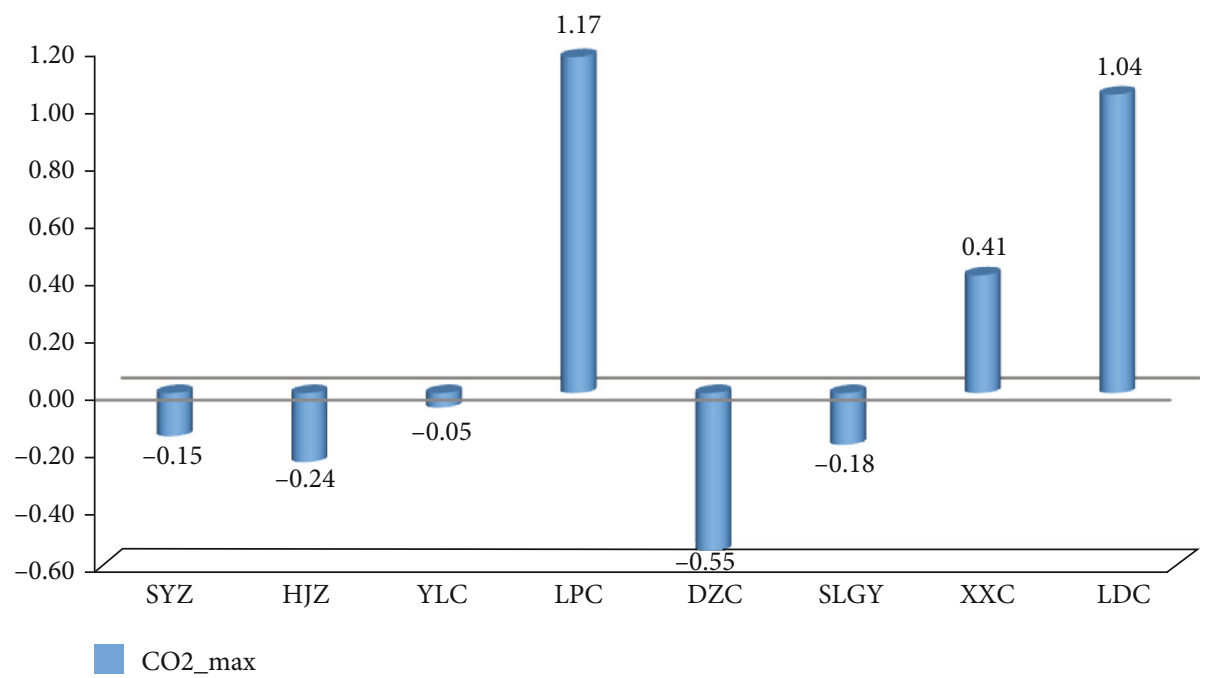

(c)

Figure 4: Continued. 


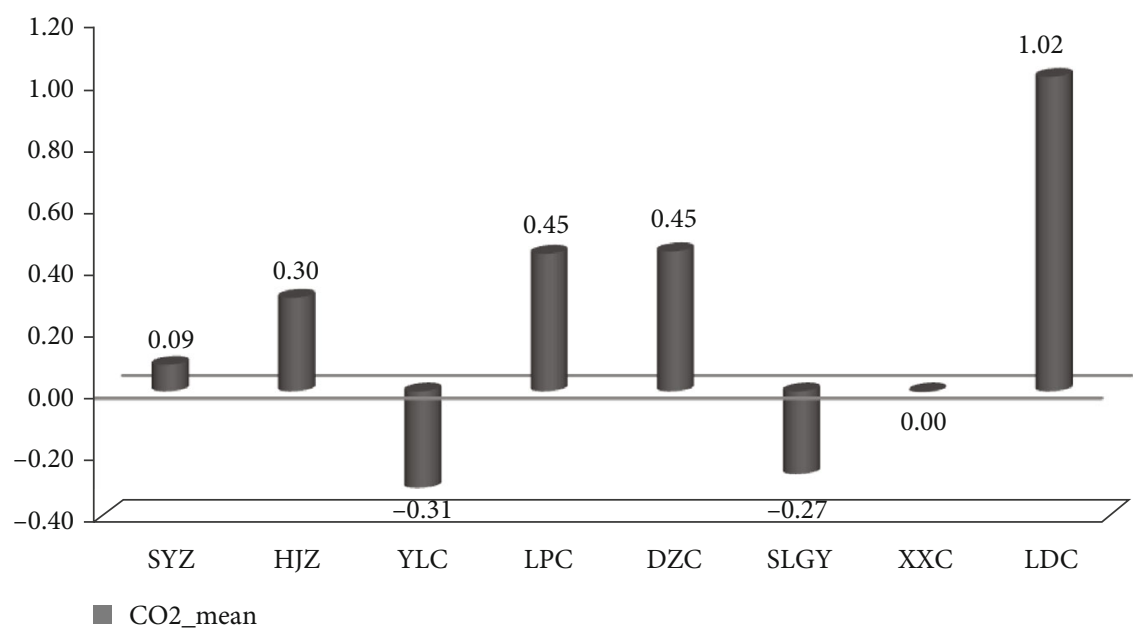

(d)

FIGURE 4: Schematic of the LPSFZ soil gas concentration change from 2017 to 2018: (a) variation of the maximum Rn, (b) variation of the mean $\mathrm{Rn}$ background value, (c) variation of the maximum $\mathrm{CO}_{2}$, and (d) variation of the mean $\mathrm{CO}_{2}$ background value.

TABLE 4: Concentration intensity results of the LPSFZ in October 2017 and October 2018.

\begin{tabular}{|c|c|c|c|c|c|c|c|c|}
\hline \multirow{2}{*}{ Site } & \multicolumn{4}{|c|}{2017.10} & \multicolumn{4}{|c|}{2018.10} \\
\hline & C_Rnmean & CRn_max & $\mathrm{CCO}_{2-}$ mean & C__ $\mathrm{CO}_{2} \max$ & C_Rnmean & CRn_max & $\mathrm{CCO}_{2 \_}$mean & C_C $\mathrm{CO}_{2} \max$ \\
\hline SYZ & 1.97 & 2.02 & 1.53 & 1.66 & 4.16 & 2.72 & 2.93 & 2.7 \\
\hline HJZ & 3.84 & 4.28 & 2.21 & 2.71 & 3.79 & 2.56 & 2.65 & 2.36 \\
\hline YLC & 4.03 & 5.13 & 3.05 & 3.15 & 3.02 & 2.4 & 5.6 & 4.78 \\
\hline LPC & 2.86 & 3.14 & 2.2 & 2.65 & 2.96 & 2.43 & 3.17 & 2.75 \\
\hline DZC & 3.26 & 3.87 & 2.44 & 2.79 & 4.47 & 3.53 & 2.91 & 2.91 \\
\hline SLGY & 2.97 & 3.15 & 1.8 & 1.84 & 2.47 & 1.94 & 3.19 & 3.19 \\
\hline $\mathrm{XXC}$ & 2.47 & 3.04 & 2.22 & 2.3 & 2.69 & 2.12 & 5.87 & 5.87 \\
\hline LDC & 2.51 & 2.87 & 2.06 & 2.36 & 2.59 & 1.98 & 3.33 & 2.76 \\
\hline
\end{tabular}

increasing trend from north to south. As for the situation where the $\mathrm{Rn}$ peak of the SYZ site in the northernmost segment has a large variation but the background value is relatively stable, the maximum value is a sudden jump phenomenon. Notably, both the measurements were performed in October, and pine leaves were shed and covered in large quantities near XXC and LDC sites in the southern segment, which would have a significant impact on soil gas concentration, particularly for $\mathrm{CO}_{2}$ concentration. We introduce the concept of concentration intensity to effectively exclude the influence of external conditions, such as soil type, meteorological conditions, sedimentary environment, and tectonic geology on other soil concentrations. The ratio of the average anomaly to the background value of a given measuring line is defined as the concentration intensity anomaly $(C)$ of the soil gas for a given site, where $C=(K+\delta) / K$, with $\delta$ as the standard deviation. The variance in the errors attributed to the different regional background conditions was minimized following this method. The mean and maximum value methods were used herein to calculate the concentration intensity [52-54].
4.2. Spatial Distribution Characteristics of the LPSFZ Concentration Intensity. Table 4 presents the calculation result of the concentration intensity of the LPSFZ. The measurement results in October 2017 (Figure 5) showed that the spatial distribution of $\mathrm{Rn}$ concentration intensity in the fault gas was strong in the north and weak in the south. The Rn concentration intensity in the YLC was the highest at 4.03 using the mean method and 5.13 using the maximum method, followed by the $\mathrm{Rn}$ concentration intensity in the HJZ, which was 3.84 and 4.28 , respectively. The concentration intensity in the southern segment was relatively small. The maximum concentration intensity in the LDC was 2.59. The mean method resulted in a concentration intensity of 1.98. The spatial distribution of $\mathrm{CO}_{2}$ concentration intensity was similar to that of $\mathrm{Rn}$, i.e., generally weak in the north and strong in the south. The maximum $\mathrm{CO}_{2}$ concentration intensity was 3.15, which was measured in the northern segment of Yanglingcun. The average concentration intensity was 3.05 (mean value method), which was the highest in the whole fault zone. The concentration intensity of the SLGY, XXC, and LDC in the southern segment was small. 

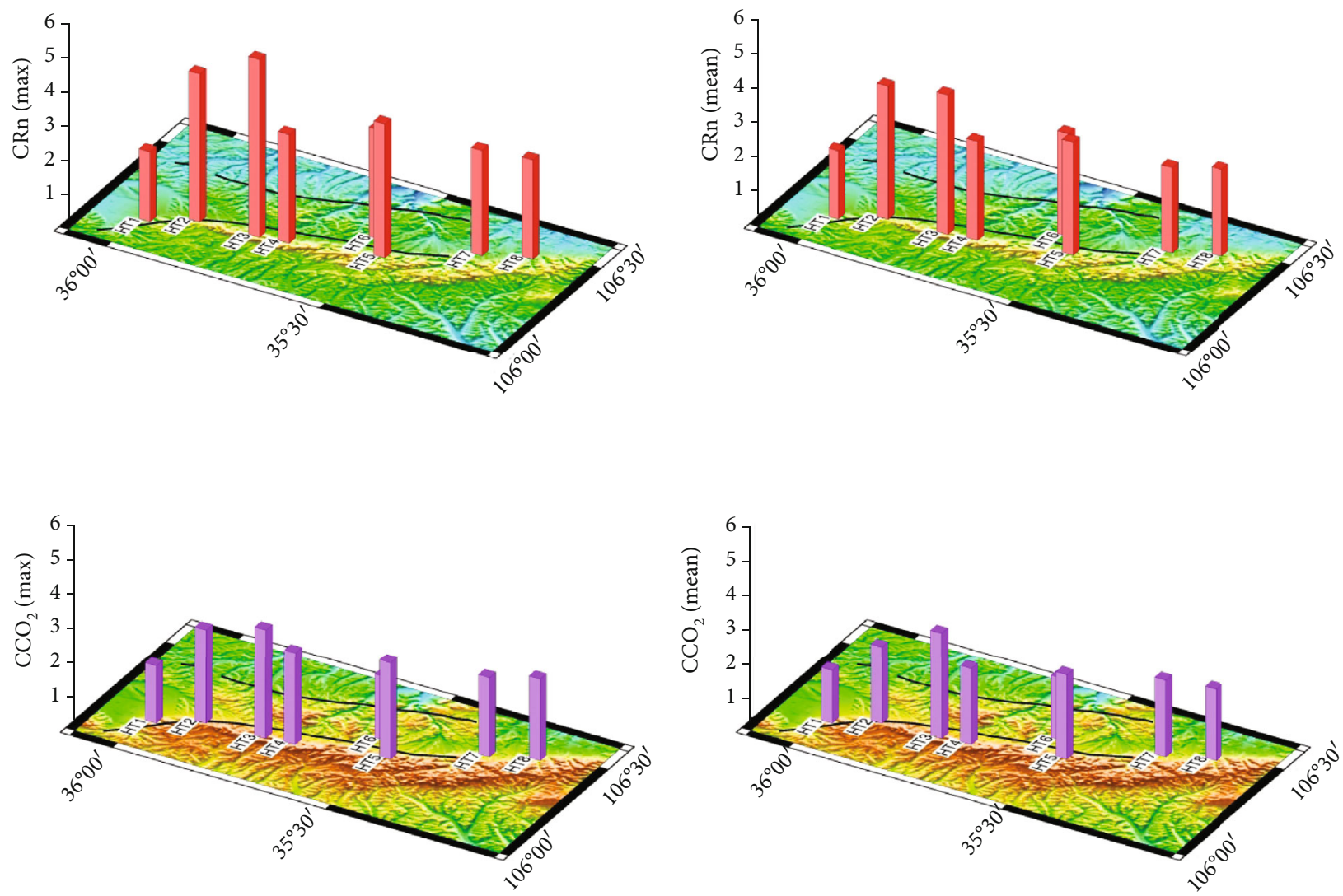

Figure 5: Spatial distribution of the LPSFZ's Rn and $\mathrm{CO}_{2}$ concentration intensity in October 2017, where CRn(max) is the maximum concentration intensity of $\mathrm{Rn} ; \mathrm{CRn}\left(\right.$ mean) is the mean concentration intensity of $\mathrm{Rn} ; \mathrm{CCO}_{2}(\mathrm{max})$ is the maximum concentration intensity of $\mathrm{CO}_{2}$; and $\mathrm{CCO}_{2}$ (mean) is the mean concentration intensity of $\mathrm{CO}_{2}$.

The measurement results in October 2018 (Figure 6) illustrate that the spatial distribution of Rn concentration intensity in the fault gas was segmented and had the same spatial distribution characteristics as those observed in October 2017, which was strong in the north and weak in the south. The Rn concentration intensity of SYZ in the northern segment was the highest. The concentration intensity measured using the mean value method was 2.72 , whereas that measured using the maximum value method was 4.16. HJZ was ranked second with a concentration intensity of 2.56 using the mean method and 3.79 using the maximum method. LPC and DZC had high concentration intensity, which was 3.53 using the mean method and 4.47 using the maximum method. Meanwhile, XXC and LDC had the lowest Rn concentration intensity, with the maximum concentration intensity of 2.69 and 2.12 and average concentration intensity of 2.59 and 1.98 , respectively. The spatial distribution of $\mathrm{CO}_{2}$ concentration intensity in the second period was similar to that of $\mathrm{Rn}$. It was also consistent with the spatial distribution of the concentration intensity in the first observation, which was generally strong in the north and weak in the south.

We compared the measured concentration intensity in 2018 with the results in 2017 (Table 5) to ensure the stability of the concentration intensity. As shown in Figure 7, Rn and $\mathrm{CO}_{2}$ were relatively stable in both the average and maximum concentration intensities. Site SYZ in the northernmost segment had the largest variation of the maximum $\mathrm{Rn}$ concentration intensity, which was 2.01, compared with the previous period. The observation values of the other sites were all close to 1 with good stability. The average concentration intensity also showed the maximum ratio in site SYZ, which was 1.61. All other sites were close to 1 with good stability. The maximum variation of $\mathrm{CO}_{2}$ was 1.76 at site SYZ in the northern segment. The results of the other sites were relatively stable, similar to $\mathrm{Rn}$.

4.3. Soil Gas Rn and $\mathrm{CO}_{2}$ Fluxes in the LPSFZ. Table 6 shows the fluxes of the soil gas $\mathrm{Rn}$ and $\mathrm{CO}_{2}$ in the LPSFZ. The maximum Rn flux was $143,297.9 \mathrm{Bqm}^{-2} \mathrm{~min}^{-1}$ in $\mathrm{HJZ}$, followed by SYZ, where the Rn flux reached $11912.2 \mathrm{Bqm}^{-2} \mathrm{~min}^{-1}$. The Rn flux in DZC reached 139,559.1 $\mathrm{Bqm}^{-2} \mathrm{~min}^{-1}$. The Rn flux of XXC and LDC in the southern segment was relatively low at $23,636.99 \mathrm{Bqm}^{-2} \mathrm{~min}^{-1}$ and $38,065.25 \mathrm{Bqm}^{-2} \mathrm{~min}^{-1}$, respectively. The $\mathrm{CO}_{2}$ flux reached its maximum value in Yanglingcun in the northern segment at $77.39 \mathrm{gm}^{-2} \mathrm{~min}^{-1}$. Meanwhile, the $\mathrm{CO} 2$ flux in $\mathrm{HJZ}$ was also relatively high at $27.68 \mathrm{gm}^{-2} \mathrm{~min}^{-1}$. The $\mathrm{CO}_{2}$ fluxes in DZC and the forest park (SLGY) were relatively high at $31.51 \mathrm{gm}^{-2} \mathrm{~min}^{-1}$ and $25.39 \mathrm{gm}^{-2} \mathrm{~min}^{-1}$, respectively. A relatively high $\mathrm{CO}_{2}$ flux was also observed in XXC, reaching $38.31 \mathrm{gm}^{-2} \mathrm{~min}^{-1}$. The $\mathrm{CO}_{2}$ flux in LDC was relatively low at only $16.56 \mathrm{gm}^{-2} \mathrm{~min}^{-1}$. 

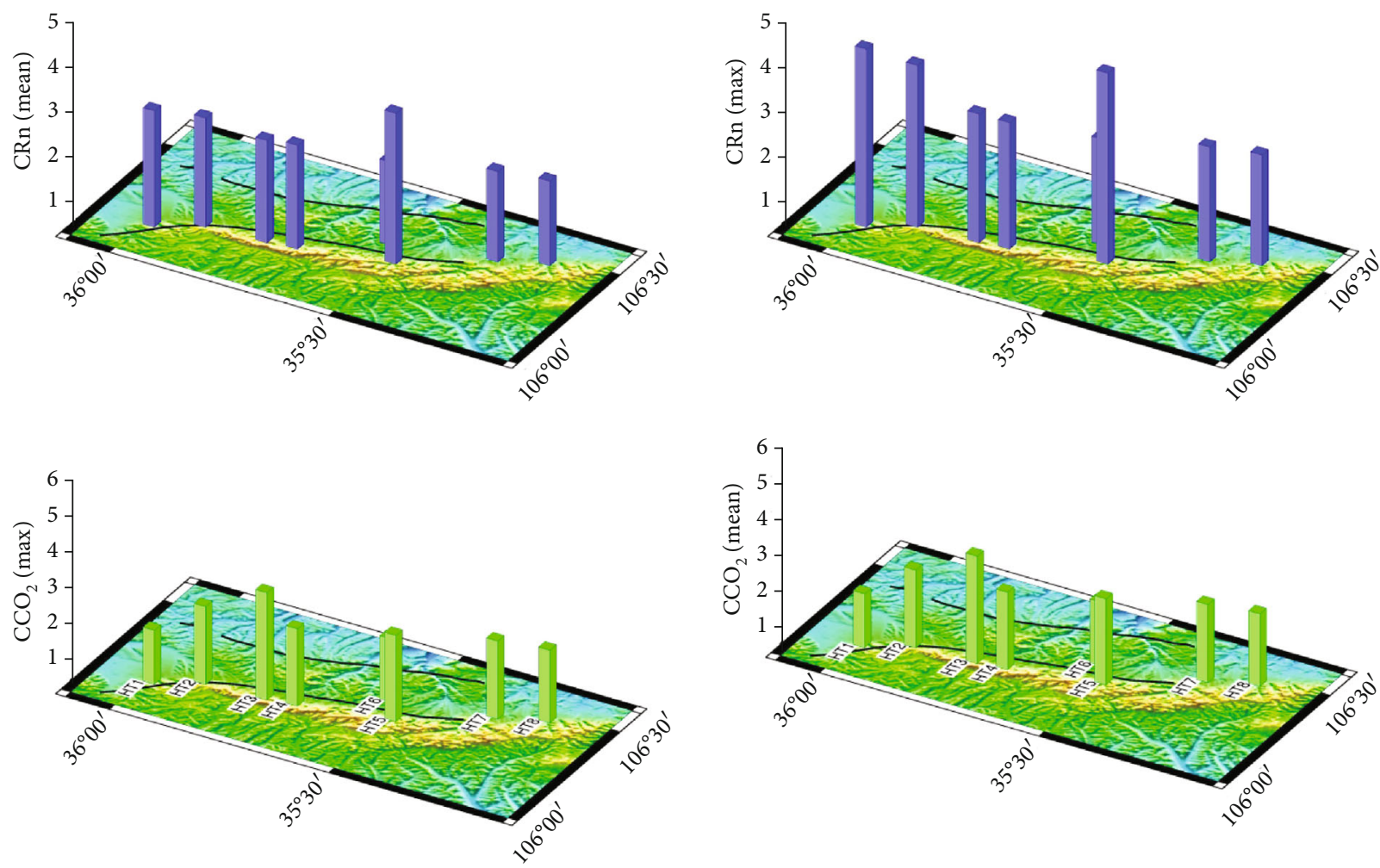

FIGURE 6: Spatial distribution of the $\mathrm{Rn}$ and $\mathrm{CO}_{2}$ concentration intensity of the LPSFZ in October 2018: CRn(mean) is the Rn maximum concentration intensity; $\mathrm{CRn}(\max )$ is the $\mathrm{Rn}$ average concentration intensity; $\mathrm{CCO}_{2}(\max )$ is the $\mathrm{CO}_{2}$ maximum concentration intensity; and $\mathrm{CCO}_{2}$ (mean) is the $\mathrm{CO}_{2}$ average concentration intensity.

TABLE 5: Comparison results of the soil gas concentration intensity between two periods of the LPSFZ.

\begin{tabular}{|c|c|c|c|c|c|c|c|c|}
\hline Site & SYZ & $\mathrm{HJZ}$ & YLC & LPC & DZC & SLGY & $\mathrm{XXC}$ & LDC \\
\hline RnSmax (2018/2017) & 2.01 & 0.97 & 1.03 & 1.06 & 1.03 & 0.77 & 0.78 & 0.94 \\
\hline RnSmean (2018/2017) & 1.61 & 1.05 & 1.02 & 1.09 & 1.29 & 0.82 & 0.87 & 0.99 \\
\hline $\mathrm{CO}_{2} \mathrm{Smax}(2018 / 2017)$ & 1.76 & 1.19 & 1.43 & 1.42 & 0.88 & 1.25 & 1.64 & 1.00 \\
\hline $\mathrm{CO}_{2}$ Smean $(2018 / 2017)$ & 0.98 & 0.85 & 0.66 & 0.81 & 0.64 & 0.77 & 0.97 & 1.16 \\
\hline
\end{tabular}

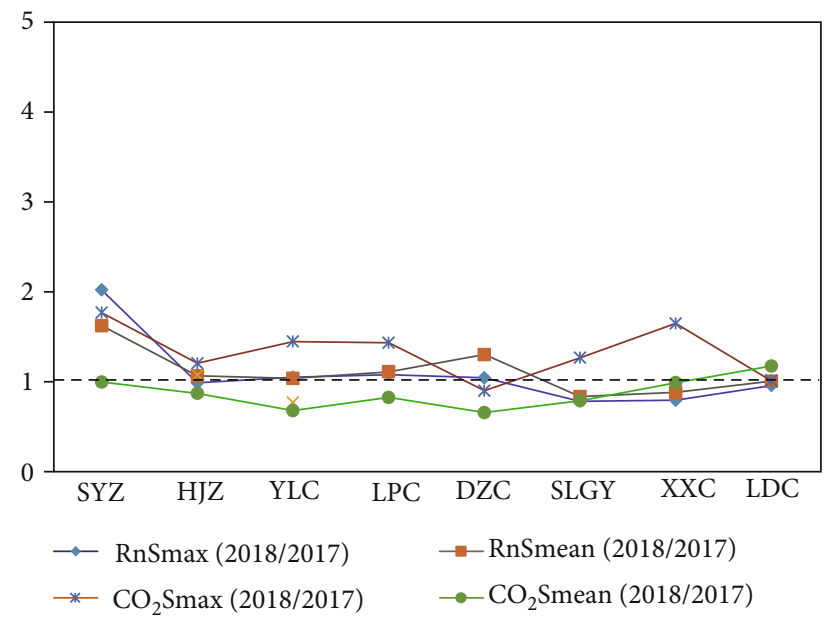

FIGURE 7: Concentration intensity of the soil gas $\mathrm{Rn}$ and $\mathrm{CO}_{2}$ in the LPSFZ.
These characteristics are consistent with the spatial distribution of the concentration intensity.

\section{Seismic Activity Characteristics in the LPSFZ}

5.1. Distribution of Historical Strong Earthquake Fracture and Seismic Gap. The LPSFZ and its adjacent active fault zones have experienced at least 11 strong and major earthquakes over the past 2000 years according to the historical record. Among these occurrences, at least five major earthquakes had a magnitude $M=7-8^{1 / 4}$, including Qishan, Shaanxi, with $M>7$ in 780 BC; southern Quyuan, Ningxia (northern Liupanshan) with M7 in 1219; Huaxian, Shanxi, with $M=81^{/ 4}$ in 1556; Zhongning, Ningxia, with $M 7^{1 / 4}$ in 1561; and northern Guyuan, Ningxia, with $M>7$ in 1622, while at least six strong earthquakes had a magnitude $M=6$ $-6^{3 / 4}[55,56]$. Most of the segments of the active fault zone in the southwestern and southern boundary of Ordos were fractured by five major earthquakes. Only two segments were 
TABLE 6: Flux results of the $\mathrm{CO}_{2}$ and $\mathrm{Rn}$ at each measurement point of the LPSFZ.

\begin{tabular}{|c|c|c|c|c|c|c|c|c|}
\hline Site & SYZ & $\mathrm{HJZ}$ & YLC & LPC & DZC & SLGY & $\mathrm{XXC}$ & LDC \\
\hline $\mathrm{CO}_{2}$ flux $\left(\mathrm{gm}^{-2} \min ^{-1}\right)$ & 7.45 & 27.68 & 77.39 & 18.04 & 31.51 & 25.39 & 38.31 & 16.56 \\
\hline Rn flux $\left(\mathrm{Bqm}^{-2} \min ^{-1}\right)$ & 119712.2 & 143297.9 & 17296.37 & 17859.43 & 139559.1 & 34532.65 & 23636.99 & 38065.25 \\
\hline
\end{tabular}

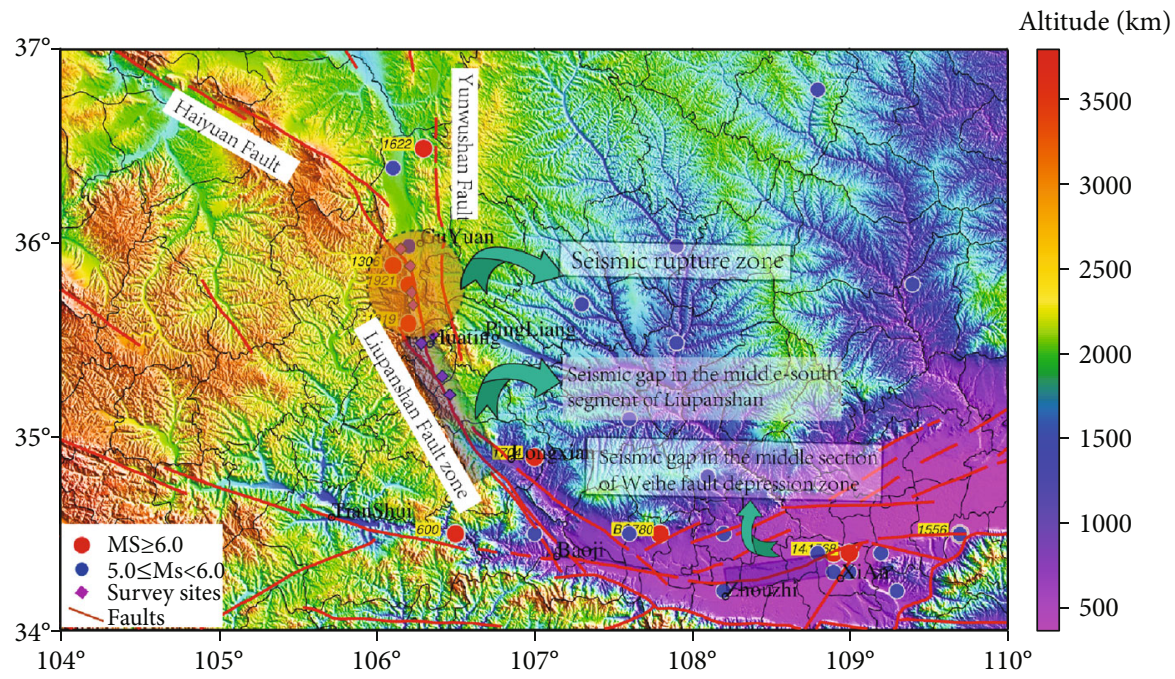

FIGURE 8: Distribution of the historical strong earthquake fracture zone in the LPSFZ area.

not fractured by major earthquakes with $M \geq 7$, which became seismic gaps. One of the seismic gaps is located between Zhou and Xi'an in the middle part of the Wei River active fault depression zone on the southern boundary of the Ordos block. The seismic gap is located in the southwestern boundary of the Ordos block between the west of Pingliang in Gansu Province and Baoji in Shaanxi Province. It is along the middle-south segment of the LPSFZ and Longxian-Baoji fault zone and can be called the seismic gap along the middlesouth segment of the LPSFZ toward Baoji [57].

Figure 8 shows a historical seismic spatial distribution map of the LPSFZ. The northern segment of the LPSFZ between the west of Pingliang and Guyuan has not only experienced at least three strong and major earthquakes in the past but also had at least six paleoseismic events that faulted the loose accumulation layer of the surface in the past 35,000 years [58]. No earthquake with $M \geq 6.5$ has been recorded in the southern part of Liupanshan between the west of Pingliang and Longxian. However, trench excavation research has found that at least three surface rupture-type paleoseismic events occurred in the past 15,000 years $[58,59]$. Therefore, a lack of $M \geq 6.5$ strong earthquake background in the seismic gap is noted along the southern segment of the LPSFZ for at least 1400 years.

5.2. Studies on the Characteristics of Current Seismic Activities in the LPSFZ. Figure 9 shows the spatial distribution of the current seismic activity of the LPSFZ. The northern segment of the LPSFZ is also the ruptured segment of three Ms 6.5-7.0 historical strong earthquakes. Three earthquakes of magnitude $\mathrm{Ms} \geq 5.0$ occurred, all of which were concentrated in the vicinity of Guyuan. Small seismic activities in this segment are also more frequent. No earthquakes of $\mathrm{Ms} \geq$ 6.0 occurred in the history of the south-central segment of the LPSFZ which mainly showed the characteristics of the sparse activity of small earthquakes nowadays. Earthquakes in seismic concentrated areas mainly occurred in Xiaoguanshan at the eastern foot of the LPSFZ and Huating area below the Pingliang fault and may be associated with the deep fault zones. However, small earthquakes in the shallow and medium seismic concentrated areas may be related to the small earthquakes induced by coal mining between Huating and Pingliang [58]. Moreover, the regions with a relatively low $b$-value in the LPSFZ were almost located in the southernmost part. Their $b$-value is generally less than 0.65 , whereas that near Huating is less than 0.55 , which is much lower than the average $b$-value of the entire study area at the same period $(0.96 \pm 0.01)$. This observation indicates a relatively high-stress accumulation. Moreover, Li et al. [60] used global positioning system (GPS) horizontal velocity field data for the China mainland; the locking and distribution of the slip deficit of the Haiyuan-LPSFZ were inverted based on a block rotation and fault locking model. At a depth of $25 \mathrm{~km}$, the locking coefficient of the south section of Liupanshan fault can still reach 0.622 , which reflects the strongest locking degree of Liupanshan fault.

\section{Conclusion and Discussion}

We can draw the following preliminary conclusions from the results of the study on the concentration, intensity, and flux of soil gas $\mathrm{Rn}$ and $\mathrm{CO}_{2}$ with eight fault survey lines on the LPSFZ: the variation of the maximum and mean values of the soil gas $\mathrm{Rn}$ and $\mathrm{CO}_{2}$ in the LPSFZ was smaller and more 


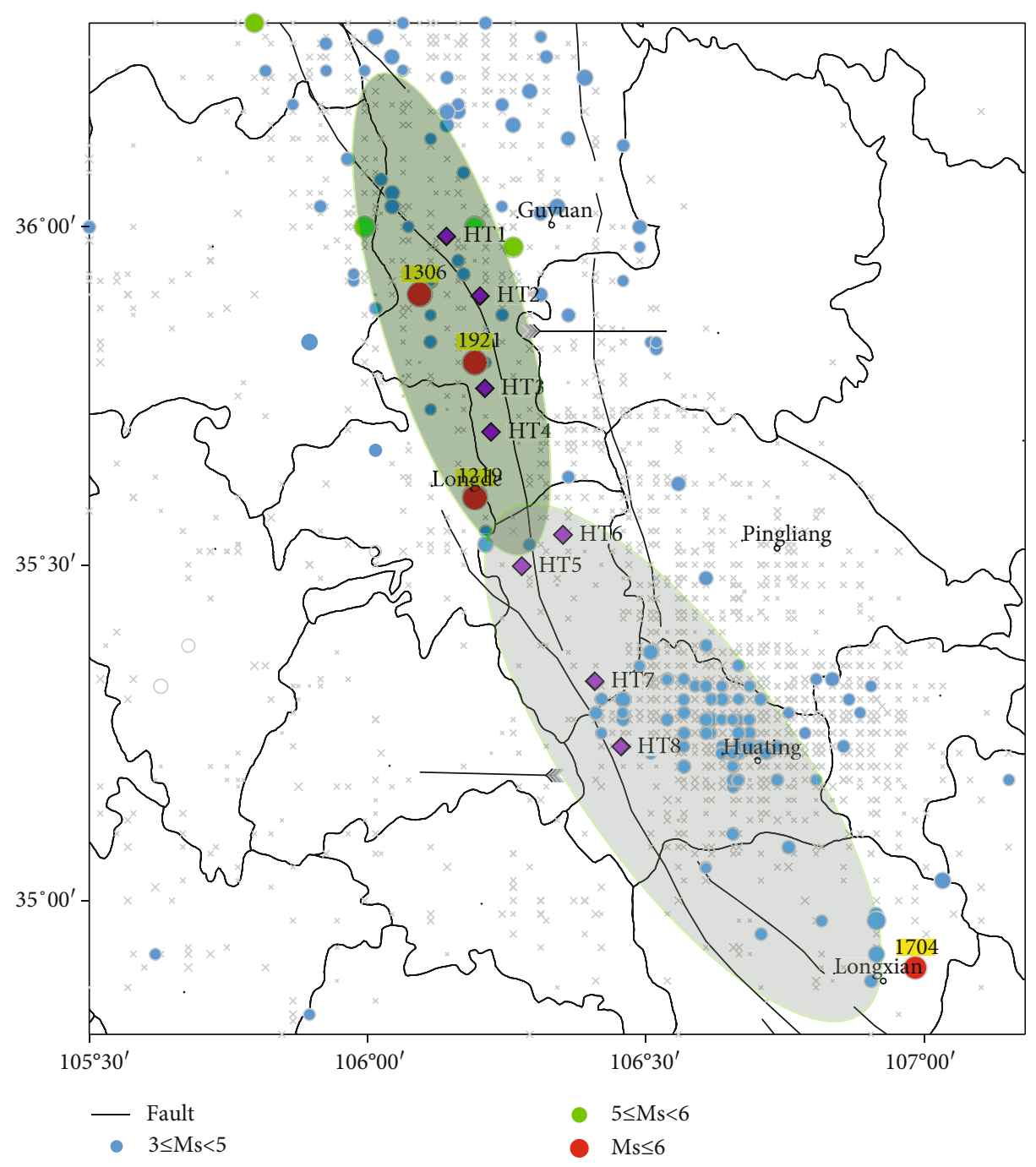

Figure 9: Present seismic distribution of the Liupanshan fault zone.

stable in the north-middle segment of the LPSFZ. However, the variation of the maximum and mean values of the soil gas $\mathrm{Rn}$ and $\mathrm{CO}_{2}$ in the LPSFZ in the southern segment was larger, showing an increasing trend from north to south. Simultaneously, the concentration intensity of the fault gas $\mathrm{Rn}$ and $\mathrm{CO}_{2}$ decreased from north to south, and the stability of the two measurement periods was high. The distribution characteristics of flux in the fault zone were also high in the north and low in the south. The spatial distribution characteristics of the concentration intensity were consistent. These results indicate that this discrepancy reflects the difference in the gas release ability of underground media. The difference in the fracture opening degree and the fault activity of different fault segments also reflect the dissimilarity of underground media and stress accumulation in different fault segments, resulting in significant differences in the venting capacity of each fault segment. The soil gas release is controlled by comprehensive factors, such as geological structure, lithology, mineralization, and soil thickness. However, the permeability of the fault zone is vital for controlling the change in the soil gas concentration intensity between faults. If the fault zone contains many tensile fractures, the deep gas can easily migrate to the surface and atmosphere, resulting in a relatively high soil gas concentration. However, if the fault zone and its fissures are in a locked state and have a low permeability, deep gas cannot migrate to the surface and will exhibit a low concentration. Conversely, if no fissure exists in the damage zone and the fault core is impermeable, the gas cannot escape from the ground and the concentration is low. The concentration in the northern segment of the LPSFZ considerably varied in the two measurement periods. The concentration intensity and flux were also large, indicating that the fault tectonic environment was relatively open and was, therefore, conducive to upward gas migration. However, the soil gas concentration in the southern segment was stable, and the concentration intensity and flux were small, denoting that the segment was in a relatively locked state.

Combined with seismicity, the northern segment of the LPSFZ is exactly the segment where three earthquakes with $M \geq 6.5$ occurred. Moreover, moderate and strong earthquakes are relatively intensive. The southern segment is 
located in the seismic gap between the middle-south segment of Liupanshan and Baoji in the southwestern boundary of the Ordos block. No seismic rupture with $M \geq 6.5$ has occurred for at least 1400 years, and small earthquakes are relatively sparse nowadays. According to the numerical simulation results based on the rate-and-state-dependent friction law, the creep of the shallow fault plane decreases or even disappears with the closure of the main segment becoming tighter in the late interseismic period. Therefore, the small seismic activities in the southern part of the LPSFZ reflect a higher degree of locking compared to those in the northern segment of the fault zone. Almost all the regions with a relatively low $b$-value of the LPSFZ are located in the southern segment. The $b$-value is generally $\leq 0.65$ and $\leq 0.55$ in the proximity of Huating, which is much lower than the average $b$-value of the entire study area in the same period $(0.96+0.01)$, thus indicating a relatively high-stress accumulation characteristic. According to the GPS velocity field data in 1999-2007 and 2008-2014, the middle-south segment of the LPSFZ has been accumulating compressive strain and levorotatory shear strain for at least the past 20 years. This observation is very similar to the horizontal transverse deformation characteristics of the Longmenshan fault zone before the 2008 Wenchuan M8.0 earthquake, which also indicates that the fault zone already has a relatively high-strain accumulation. The distribution characteristics of the soil gas $\mathrm{Rn}$ and $\mathrm{CO}_{2}$ in the LPSFZ correspond well with its seismic activity. The soil gas concentration in the northern segment with a strong seismic activity considerably varies, and the concentration intensity and flux are relatively high. The seismic activity in the southern segment is very low, and the corresponding changes in the soil gas $\mathrm{Rn}$ and $\mathrm{CO}_{2}$ concentration are very low. Moreover, the concentration intensity and flux are relatively small. These results indicate that the fault plane of the southern segment of the LPSFZ is in a locked state. Furthermore, the main fault zone in the locked area has Quaternary-Holocene activities. Three strong or large earthquakes of a surface rupture type occurred in the last 15,000 years, and they have been inferred to have the ability and background to produce major/strong earthquakes.

Previous long-term studies on the great earthquakes $(\mathrm{Ms} \geq 6.0)$ that have occurred both globally and on the Chinese mainland have found that such earthquakes do not occur within the high-seismicity zones of fault systems but rather within or near seismic gaps. However, the earthquake mechanisms that shape the seismicity observed within the seismic gaps and other low-seismicity zones are still unclear, even though the ability to predict great earthquakes is a fundamental requirement for effective earthquake mitigation. The concept of asperity or strong patch of the fault has been proposed to qualitatively explain the seismic gap, termed as the sturdy body seismogenic model. The same situation exists for weakly deformed regions, such as the one-to-five-year period preceding the 1976 Tangshan Ms7.6 earthquake, where distinct deformation was observed in the area surrounding a relatively stable zone, which was termed a weakly deformed region. A comprehensive GPS analysis of China's crustal movement observation network following the 2008 Wenchuan Ms8.0 earthquake indicated that the high-strain zone did not lie along the Longmenshan fault but rather was concentrated in the Xianshui River-Anning-Zemu River area, suggesting that the seismic fault of the Wenchuan earthquake was a weaker deformation fault in the syntectonic region. Furthermore, a geothermal study in the area south of Zhangjiakou, Hebei Province, China, showed that strong earthquakes mainly occur in areas with relatively weaker subsurface fluid activities. This is consistent with our research results in the northern margin of the West Qinling and Qilian fault zones. Various seismic observations indicate that the seismogenic sites are all in a relatively quiet state, with the source area of each strong earthquake characterized as a locked fault zone. Therefore, the southern segment of the LPSFZ should be a potential hazardous segment for major/strong earthquakes in the future.

\section{Data Availability}

Data used to support the findings of this study are included within the supplementary information files. The data are available from the corresponding author upon request after publication of this paper.

\section{Conflicts of Interest}

The authors declare that they have no conflicts of interest.

\section{Acknowledgments}

This work is supported by the basic R\&D fund of the Institute of Earthquake Science, China Earthquake Administration (CEA) (Grant 2017IESLZ01 and 2018IESLZ05), the Gansu province science and technology plan project (Grant 1606RJYA218), and the Spark Program of China Earthquake Administration (Grant XH15043).

\section{Supplementary Materials}

Data used to support the findings of this study are included within the supplementary information files. (Supplementary Materials)

\section{References}

[1] Y. Y. Kagan and D. D. Jackson, "Earthquake forecasting in diverse tectonic zones of the globe," Pure and Applied Geophysics, vol. 167, no. 6-7, pp. 709-719, 2010.

[2] M. D. Zoback, "Seismology: earthquake forecasting and warning," Science, vol. 222, no. 4621, p. 319, 1983.

[3] R. J. Zhou, R. C. Tang, Z. Z. Huang, Y. Lin, T. Yang, and W. Zhou, "Tectonic deformation and strong earthquake activities on the east border of Tibet Plateau," Earth Science Frontiers, vol. z1, pp. 297-298, 2000.

[4] Z. Chen, Y. Li, Z. Liu, C. Lu, Y. Zhao, and J. Wang, "Evidence of multiple sources of soil gas in the Tangshan fault zone, North China," Geofluids, vol. 2019, Article ID 1945450, 12 pages, 2019.

[5] G. Ciotoli, S. Lombardi, and A. Annunziatellis, "Geostatistical analysis of soil gas data in a high seismic intermontane basin: 
Fucino Plain, central Italy," Journal of Geophysical Research, vol. 112, no. B5, article B05407, 2007.

[6] Z. Chen, Y. Li, Z. Liu, J. Wang, X. Zhou, and J. Du, "Radon emission from soil gases in the active fault zones in the capital of China and its environmental effects," Scientific Reports, vol. 8, no. 1, article 16772, 2018.

[7] T. Doğan, H. Sumino, K. Nagao, K. Notsu, M. K. Tuncer, and C. Çelik, "Adjacent releases of mantle helium and soil $\mathrm{CO}_{2}$ from active faults: observations from the Marmara region of the North Anatolian Fault zone, Turkey," Geochemistry, Geophysics, Geosystems, vol. 10, no. 11, 2009.

[8] C. C. Fu, T. F. Yang, C. H. Chen et al., "Spatial and temporal anomalies of soil gas in northern Taiwan and its tectonic and seismic implications," Journal of Asian Earth Sciences, vol. 149, pp. 64-77, 2017.

[9] V. Walia, S. J. Lin, C. C. Fu et al., "Soil-gas monitoring: a tool for fault delineation studies along Hsinhua Fault (Tainan), Southern Taiwan," Applied Geochemistry, vol. 25, no. 4, pp. 602-607, 2010.

[10] J. P. Toutain, J. C. Baubron, J. Le Bronec et al., "Continuous monitoring of distal gas emanations at Vulcano, southern Italy," Bulletin of Volcanology, vol. 54, no. 2, pp. 147-155, 1992.

[11] G. Ciotoli, M. Guerra, S. Lombardi, and E. Vittori, "Soil gas survey for tracing seismogenic faults: a case study in the Fucino basin, Central Italy," Journal of Geophysical Research: Solid Earth, vol. 103, no. B10, pp. 23781-23794, 1998.

[12] G. Ciotoli, G. Etiope, M. Guerra, and S. Lombardi, "The detection of concealed faults in the Ofanto Basin using the correlation between soil-gas fracture surveys," Tectonophysics, vol. 301, no. 3-4, pp. 321-332, 1999.

[13] F. Italiano, G. Martinelli, and P. Plescia, " $\mathrm{CO}_{2}$ degassing over seismic areas: the role of mechanochemical production at the study case of Central Apennines," Pure and Applied Geophysics, vol. 165, no. 1, pp. 75-94, 2008.

[14] C. Y. King, "Gas geochemistry applied to earthquake prediction: an overview," Journal of Geophysical Research: Solid Earth, vol. 91, no. B12, pp. 12269-12281, 1986.

[15] A. Sciarra, B. Cantucci, and M. Coltorti, "Learning from soil gas change and isotopic signatures during 2012 Emilia seismic sequence," Scientific Reports, vol. 7, no. 1, article 14187, 2017.

[16] G. Iovine, I. Guagliardi, C. Bruno et al., "Soil-gas radon anomalies in three study areas of Central-Northern Calabria (Southern Italy)," Natural Hazards, vol. 91, no. 1, pp. 193219, 2017.

[17] J. L. Lewicki, W. C. Evans, G. E. Hilley, M. L. Sorey, J. D. Rogie, and S. L. Brantley, "Shallow soil $\mathrm{CO}_{2}$ flow along the San Andreas and Calaveras faults, California," Journal of Geophysical Research: Solid Earth, vol. 108, no. B4, 2003.

[18] Y. Li, J. du, X. Wang, X. Zhou, C. Xie, and Y. Cui, "Spatial variations of soil gas geochemistry in the Tangshan area of Northern China," Terrestrial, Atmospheric and Oceanic Sciences, vol. 24, no. 3, pp. 323-332, 2011.

[19] C.-C. Fu, T. F. Yang, V. Walia et al., "Variations of soil-gas composition around the active Chihshang Fault in a plate suture zone, eastern Taiwan," Radiation Measurements, vol. 44, no. 9-10, pp. 940-944, 2009.

[20] J. P. Toutain and J. C. Baubron, "Gas geochemistry and seismotectonics: a review," Tectonophysics, vol. 304, no. 1-2, pp. 1-27, 1999.
[21] T. F. Yang, C. C. Fu, V. Walia et al., "Seismo-geochemical variations in SW Taiwan: multi-parameter automatic gas monitoring results," Pure and Applied Geophysics, vol. 163, no. 4, pp. 693-709, 2006.

[22] L. L. Chyi, T. J. Quick, T. F. Yang, and C. H. Chen, "The experimental investigation of soil gas radon migration mechanisms and its implication in earthquake forecast," Geofluids, vol. 10, no. 4, pp. 556-563, 2010.

[23] C. Y. King, "Radon emanation on San Andreas Fault," Nature, vol. 271, no. 5645, pp. 516-519, 1978.

[24] S. Džeroski, L. Todorovski, B. Zmazek, J. Vaupotic, and I. Kobal, "Modelling soil radon concentration for earthquake prediction," in Discovery Science, vol. 2843, pp. 87-99, Springer, 2003.

[25] K. Kharatian, Y. Travi, and V. Igoumnov, “Activité du gaz radon dans l'air du sol et sismicité locale : exemple du bassin de l'Arax (Arménie)," Comptes Rendus Geoscience, vol. 334, no. 3, pp. 179-185, 2002.

[26] C. M. Wang, Y. T. Che, D. K. Wan, and S. Y. Dong, Microdynamics of underground water, Seismological Press, Beijing, 1988.

[27] Y. W. Liu, H. J. Chen, and Y. T. Che, "Retrospect and prospect of observation and study on seismic underground fluid in China," Recent Developments in World Seismology, vol. 331, no. 7, pp. 3-12, 2006.

[28] Y. T. Che, J. Z. Yu, and W. Z. Liu, "The hydrodynamic mechanism of water radon anomaly," Seismology and Geology, vol. 19, no. 4, pp. 353-356, 1997.

[29] C. M. Wang, X. H. Li, and B. L. Wei, Application of fault gas measurement to earthquake science, Seismological Press, Beijing, 1991.

[30] J. G. Du, W. X. Yu, S. Q. Li et al., "The geochemical characteristics of escaped radon from the Babaoshan fault zone and its earthquake reflecting effect," Earth, vol. 18, no. 2, pp. 155161, 1998.

[31] C. Tansi, A. Tallarico, G. Iovine, M. Folino Gallo, and G. Falcone, "Interpretation of radon anomalies in seismotectonic and tectonic-gravitational settings: the south-eastern Crati graben (Northern Calabria, Italy)," Tectonophysics, vol. 396, no. 3-4, pp. 181-193, 2005.

[32] J. Kemski, R. Klingel, H. Schneiders, A. Siehl, and J. Wiegand, "Geological structure and geochemistry controlling radon in soil gas," Radiation Protection Dosimetry, vol. 45, no. 1-4, pp. 235-239, 1992.

[33] J. C. Baubron, A. Rigo, and J. P. Toutain, "Soil gas profiles as a tool to characterise active tectonic areas: the Jaut Pass example (Pyrenees, France)," Earth and Planetary Science Letters, vol. 196, no. 1-2, pp. 69-81, 2002.

[34] F. Viveiros, C. Cardellini, T. Ferreira, S. Caliro, G. Chiodini, and C. Silva, "Soil CO2emissions at Furnas volcano, São Miguel Island, Azores archipelago: volcano monitoring perspectives, geomorphologic studies, and land use planning application," Journal of Geophysical Research: Solid Earth, vol. 115, no. B12, 2010.

[35] F. Tassi, B. Nisi, C. Cardellini et al., "Diffuse soil emission of hydrothermal gases $\left(\mathrm{CO}_{2}, \mathrm{CH}_{4}\right.$, and $\left.\mathrm{C}_{6} \mathrm{H}_{6}\right)$ at Solfatara crater (Campi Flegrei, southern Italy)," Applied Geochemistry, vol. 35, pp. 142-153, 2013.

[36] Y. Fan and Z. H. Che, "The fault activity in recent time along northern section of North-South Seismic Belt and its both sides," Earth, vol. 21, no. 2, pp. 87-93, 2001. 
[37] W. J. Yan, H. W. Tu, and W. Dai, "Medium-term prediction of earthquakes with $\mathrm{M}=7$ or above in the North-South Seismic Belt," Plateau Earthquake, vol. 20, no. 4, pp. 14-20, 2008.

[38] X. W. Xu, X. Z. Wen, and J. Q. Ye, "Surface rupture zone and seismogenic structure of Wenchuan $\mathrm{M}_{\mathrm{S}} 8.0$ earthquake," Seismological Geology, vol. 30, no. 3, pp. 597-629, 2008.

[39] D. Y. Yuan, Z. S. Lei, J. L. Zhang, B. C. Liu, and M. J. Liang, "Textural research of 1219 A.D. Guyuan earthquake in Ningxia Hui Autonomous Region,China, and discuss on its csusative structure," Acta Seismologica Sinica, vol. 30, no. 6, pp. 648-657, 2008.

[40] P. Z. Zhang, Q. D. Deng, and G. M. Zhang, "Strong seismicity and active block in mainland China," Science China (SeriesD), vol. 33, Supplement 1, pp. 12-20, 2003.

[41] F. Du, X. Z. Wen, M. J. Liang, and F. Long, "GPS deformation characteristics and seismic risk background in the middle south section of Liupanshan fault," International Earthquake Dynamics, vol. 9, pp. 18-18, 2015.

[42] D. Y. Yuan, Z. S. Lei, J. L. Zhang, B. C. Liu, and M. J. Liang, "Textual research of 1219 A.D. Guyuan earthquake in Ningxia Hui Autonomous Region, China and discussion on its causative structure," Acta Seismologica Sinica, vol. 21, no. 6, pp. 652-664, 2008.

[43] V. M. Choubey, K. S. Bist, N. K. Saini, and R. C. Ramola, "Relation between soil-gas radon variation and different lithotectonic units, Garhwal Himalaya, India," Applied Radiation and Isotopes, vol. 51, no. 5, pp. 587-592, 1999.

[44] Y. Ben-Zion and C. G. Sammis, "Characterization of fault zones," Pure and Applied Geophysics, vol. 160, no. 3, pp. 677-715, 2003.

[45] N. Segovia, J. L. Seidel, and M. Monnin, "Variations of radon in soils induced by external factors," Journal of Radioanalytical and Nuclear Chemistry, vol. 119, no. 3, pp. 199-209, 1987.

[46] P. Tuccimei and M. Soligo, "Correcting for CO2 interference in soil radon flux measurements," Radiation Measurements, vol. 43, no. 1, pp. 102-105, 2008.

[47] I. Forbrich, L. Kutzbach, A. Hormann, and M. Wilmking, "A comparison of linear and exponential regression for estimating diffusive CH4 fluxes by closed-chambers in peatlands," Soil Biology and Biochemistry, vol. 42, no. 3, pp. 507-515, 2010.

[48] C. Jiang, G. Yu, G. Cao, Y. Li, S. Zhang, and H. Fang, " $\mathrm{CO}_{2}$ flux estimation by different regression methods from an alpine meadow on the Qinghai-Tibetan Plateau," Advances in Atmospheric Sciences, vol. 27, no. 6, pp. 1372-1379, 2010.

[49] T. Nakano, T. Sawamoto, T. Morishita, G. Inoue, and R. Hatano, "A comparison of regression methods for estimating soil-atmosphere diffusion gas fluxes by a closed-chamber technique," Soil Biology and Biochemistry, vol. 36, no. 1, pp. 107-113, 2004.

[50] W. C. Evans, M. L. Sorey, B. M. Kennedy, D. A. Stonestrom, J. D. Rogie, and D. L. Shuster, "High $\mathrm{CO}_{2}$ emissions through porous media: transport mechanisms and implications for flux measurement and fractionation," Chemical Geology, vol. 177, no. 1-2, pp. 15-29, 2001.

[51] T. M. Gerlach, M. P. Doukas, K. A. McGee, and R. Kessler, "Soil efflux and total emission rates of magmatic $\mathrm{CO} 2$ at the Horseshoe Lake tree kill, Mammoth Mountain, California, 1995-1999," Chemical Geology, vol. 177, no. 1-2, pp. 101$116,2001$.

[52] C. Li, H. Zhang, H. Su, H. Zhou, and Y. Wang, "Spatial distribution correlation of soil-gas radon $\left({ }^{222} \mathrm{Rn}\right)$ and mercury with leveling deformation in northern margin fault zone of West Qinling, China," Journal of Environmental Radioactivity, vol. 178-179, pp. 315-324, 2017.

[53] H. Zhou, H. Su, H. Zhang, and C. Li, "Correlations between soil gas and seismic activity in the Generalized Haiyuan Fault Zone, north-central China," Natural Hazards, vol. 85, no. 2, pp. 763-776, 2017.

[54] H. Zhou, H. Su, H. Zhang, and C. Li, "Optimizing a soil gas monitoring network layout across faults based on a seismogenic model," Applied Geochemistry, vol. 104, pp. 184-192, 2019.

[55] Z. G. Shi, Z. S. Lei, and D. Y. Yuan, "TexturaI research the Guyuan earthquake in 1306 in Ningxia Region,and discussi on its seismogenic structure," Northwestern Seismological Journal, vol. 33, no. 4, pp. 342-348, 2011.

[56] Z. G. Shi, T. D. Li, and D. Y. Yuan, "The recent active time of the south segment of the eastern Li upanshan piedmont fault: constraints from the characteristics of rhythmic deposits in the fault grooves," Acta Geoscientica Sinica, vol. 35, no. 1, pp. 3137, 2014.

[57] F. Du, X. Z. Wen, J. G. Feng, M. J. Liang, F. Long, and J. Wu, "Seismotecton ics and seismic potential of the Liupanshan fault zone (LPSFZ), China," Chinese Journal of Geophysics, vol. 61, no. 2, pp. 545-557, 2018.

[58] G. D. Yang, Y. X. Wu, and H. Xu, "Study on the strengthening small earthquake activity phenomenon in Huating region," Northwestern Seismological Journal, vol. 28, no. 2, pp. 163$166,2006$.

[59] H. F. Xiang, Y. A. Aikeda, and W. X. Zhang, "Study on paleo earthquakes of the eastern Liupanshan piedmont fault zone," Earthquake Research in China, vol. 15, no. 1, pp. 74-81, 1999.

[60] Q. Li, Z. S. Jiang, Y. Q. Wu, and J. Zhao, "Inversion of locking and distribution of slip deficit in Haiyuan-Liupan fault zone using GPS data," Geomatics and Information Science of Wuhan University., vol. 39, no. 5, pp. 576-579, 2014. 